\title{
Recognition of adverse drug events in older hospitalized medical patients
}

\author{
Joanna E. Klopotowska • Peter C. Wierenga • \\ Susanne M. Smorenburg • Clementine C. M. Stuijt • \\ Lambertus Arisz • Paul F. M. Kuks • \\ Marcel G. W. Dijkgraaf • Loraine Lie-A-Huen • \\ Sophia E. de Rooij • \\ on behalf of the WINGS study group
}

Received: 16 January 2012 / Accepted: 14 May 2012 /Published online: 7 June 2012

(C) The Author(s) 2012. This article is published with open access at Springerlink.com

\begin{abstract}
Objective To assess medical teams' ability to recognize adverse drug events (ADEs) in older inpatients.

Methods The study cohort comprised 250 patients aged 65 years or older consecutively admitted to Internal Medicine wards of three hospitals in the Netherlands between April and November 2007. An independent expert team identified ADEs present upon admission or occurring during hospitalization by a structured retrospective patient chart
\end{abstract}

Trial registration: International Standard Randomized Controlled Trial Number Register ISRCTN64974377

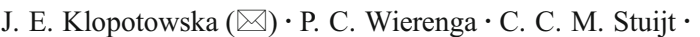

P. F. M. Kuks $\cdot$ L. Lie-A-Huen

Department of Hospital Pharmacy, Academic Medical Centre,

Meibergdreef 9 ,

1105 AZ Amsterdam, The Netherlands

e-mail: j.e.klopotowska@amc.nl

P. C. Wierenga

Department of Hospital Pharmacy, Deventer Hospital,

Nico Bolkesteinlaan 75,

7416 SE Deventer, The Netherlands

S. M. Smorenburg $\cdot$ S. E. de Rooij

Section of Geriatrics, Department of Internal Medicine, Academic

Medical Centre,

Meibergdreef 9,

1105 AZ Amsterdam, The Netherlands

L. Arisz

Department of Internal Medicine, Academic Medical Centre,

Meibergdreef 9 ,

1105 AZ Amsterdam, The Netherlands

M. G. W. Dijkgraaf

Clinical Research Unit, Academic Medical Centre,

Meibergdreef 9 ,

1105 AZ Amsterdam, The Netherlands review. For all ADEs identified, the expert team assessed causality, severity, preventability, and recognition by medical teams.

Results The medical teams did not recognize $19.9 \%$ of all ADEs present upon admission $\{60.4$ ADEs [95\% confidence interval (CI) 51.5-70.8] per 100 hospitalizations and $20.3 \%$ of all ADEs occurring during the hospital stay [47.2 ADEs (95\% CI 39.4-56.5) per 100 hospitalizations]. Unrecognized ADEs were significantly more often ADEs with possible causality $(\mathrm{p}=0.014, \mathrm{df}=1)$, ADEs caused by medication errors $(\mathrm{p}<0.001, \mathrm{df}=1)$, and ADEs not manifesting as new symptoms $(\mathrm{p}<0.001, \mathrm{df}=1)$. The medical teams did not recognize $23.2 \%$ of mild to moderately severe ADEs and $16.5 \%$ of severe, life-threatening, or fatal ADEs. The recognition of ADEs varied with event type.

Conclusions The recognition of ADEs by medical teams was substantial for those ADEs with evident causality and with clinically apparent and severe consequences. ADEs mimicking underlying pathologies with a lower severity went unrecognized much more often, as did those resulting only in abnormal laboratory values. Tools to improve the recognition of ADEs by medical teams should, therefore, focus on those ADEs that are more challenging to detect.

Keywords Adverse drug events · Medication safety · Elderly $\cdot$ Hospital

\section{Introduction}

Adverse Drug Events (ADEs) are the most frequent type of adverse events in medical inpatients [1] and are associated with a prolonged hospital stay, a twofold increase in the risk of death, and higher costs [2]. Approximately $50 \%$ of ADEs 
are preventable [3]. A widely accepted definition of an ADE is any harm occurring during drug therapy which may result from either appropriate care (non-preventable ADE) or from suboptimal care (preventable ADE) (i.e., a medication error) [4].

It is widely acknowledged that older patients are especially at risk for ADEs $[5,6]$, primarily due to multiple comorbidities, polypharmacy, and higher vulnerability due to decreased organ function, increased susceptibility to drugs, and frequently present cognitive impairment [7, 8]. Furthermore, correct and timely diagnosis is often hampered by atypical disease presentation, such as falls or delirium [5, 9]. Therefore, not only avoiding ADEs in older inpatients, but also, when they do occur, timely recognition of ADEs may pose a significant challenge for medical teams $[9,10]$. Failure to recognize ADEs during the hospital stay may lead to inappropriate actions causing even more harm [10]. The study by Nebeker et al. [11] reports that in a general inpatient population, $24 \%$ of ADEs subsequently identified by the researchers were not recognized by the medical teams.

Although the body of literature on the occurrence of (preventable) ADEs in older hospitalized patients is extensive $[5,12-22]$, data on medical teams' ability to timely recognize ADEs in this vulnerable patient population are limited to the Emergency Department setting [23].

Therefore, we conducted a multicenter cohort study with the aim to gain a detailed insight into recognition of ADEs by medical teams in older inpatients. In order to do so, both ADEs present upon admission and those occurring during the hospital stay were included in our analysis.

\section{Material and methods}

\section{Study setting}

The study was performed in the Internal Medicine wards of three teaching hospitals in the Netherlands: the Academic Medical Center (AMC) in Amsterdam, a 1,002-bed academic hospital, the Westfriesgasthuis (WFG) in Hoorn, a 506bed regional teaching hospital, and the Spaarne Hospital (SH) in Hoofddorp, a 520-bed tertiary teaching hospital. The Internal Medicine wards were staffed by teams consisting of attending physicians, junior and senior residents, and interns on rotation, caring together for an average of ten adult patients daily. All three Hospital Pharmacy Departments offered only off-ward, daily clinical services, including preparation of parenteral medications by pharmacy technicians, on-call availability of a hospital pharmacist for pharmacotherapeutic or toxicological consultations, and therapeutic drug monitoring (TDM). In addition, Computerized Physician Order Entry (CPOE) systems with limited clinical decision support were in place in all three participating hospitals. These clinical decision support systems (CDSSs) generated three types of alerts based only on the prescribing data: drug-drug interactions, drug-drug duplications, and overdoses. No other sources, such as laboratory values or diagnostic tests results, were linked to these operating CDSSs.

\section{Study design}

Data presented in this study are baseline results of an interrupted time-series study on the effects of the Ward-oriented pharmacy In Newly admitted Geriatric Seniors (WINGS) study [24]. Over a period of 8 months (April-November 2007), 250 patients aged 65 years or older were included in the study during three sampling periods: 90,80 , and 80 consecutively admitted patients were enrolled during the first (April-May 2007), second (July-August 2007) and third (October-November 2007) sampling period, respectively.

The WINGS study was conducted within the framework of the CAREFUL (pharmacist Coordinated ADE Reducing Efforts For Use in all Levels of healthcare) research program based on a cooperative effort between Leiden University Medical Center, AMC Amsterdam, University Medical Center Groningen, and University Medical Center Utrecht/ Utrecht University.

\section{Patients}

All patients aged 65 years or older who were taking five or more medications on the day of admission and who were admitted to an Internal Medicine ward of the participating hospitals during one of the three sampling periods were eligible for enrolment in the study. Patients were excluded if they were scheduled for chemotherapy, radiation therapy, or stem cell/kidney transplantation, were discharged within $24 \mathrm{~h}$, and/or had been transferred from other hospitals or other non-medical wards within the study hospitals. Only the first hospitalization during the baseline period per each included patient was reviewed (index hospitalization). The index hospitalization included the day of admission and all days of the subsequent hospitalization until the patient was discharged home, transferred to a non-medical ward within the same hospital, or transferred to another healthcare facility (e.g., hospital, nursing home).

\section{Measurement and classification of ADEs}

No golden standard currently exists for the measurement, definition, and assessment of ADEs [25, 26]. The definitions used in this study, as well as the method and assessment of ADEs follow recommendations by experts and are also widely accepted [4, 26-28]. An ADE was classified as any 
harmful event occurring during drug therapy that resulted either from appropriate care (non-preventable ADEs) or from medication errors (preventable ADE) [4]. Both errors of omission or commission were included in this study. Harmful events were defined as either abnormal laboratory values or clinical symptoms. ADEs were included if they resulted in an outbreak of new symptoms/pathology, in worsening of existing or new symptoms/pathology, or in a delay or lack of any expected improvement of existing or new symptoms/pathology [4].

A detailed description of the method applied in this study can be found elsewhere [24]. In summary, after an included patient was discharged or transferred, trained research nurses and pharmacy students first gathered all information available on the index hospitalization (medical and nurse patients' files, medication charts, discharge letters and other medical correspondence, laboratory and diagnostic results) and completed a case report form (CRF) in which 'socalled' triggers were incorporated. These triggers were adapted from the Institute of Healthcare Improvement (IHI) ADE trigger-tool [29]. Examples of IHI ADE triggers are the ordering of vitamin $\mathrm{K}$ which may be related to overanticoagulation with coumarines, or a digoxin level of $>2.0 \mu \mathrm{g} / \mathrm{L}$ which may be related to digoxin toxicity. These triggers were ticked off by the researchers when applicable, with an aim to prompt expert team attention to specific events which may potentially be ADEs [30]. Second, the information collected on the index hospitalization together with the CRFs were presented to two independent experts, namely, a senior specialist in Internal Medicine (LA) and a senior clinical pharmacist specializing in geriatric medicine (CS), both of whom were experienced in systematic ADE identification. These two experts reviewed all data independently and subsequently discussed their findings during scheduled meetings. A structured ADE assessment was used to determine the causality between a drug and an adverse event, preventability and severity of an ADE, recognition of ADEs by medical teams, and, when applicable, type of underlying medication error. Only ADEs with a causality score of nearly certain, probable, and possible, as assessed according to the World Health Organization-Uppsala Medical Centre (WHO-UMC) criteria were included [31]. ADEs caused by a medication error were classified as preventable. The severity of an ADE was scored according to Common Terminology Criteria for Adverse Events ver. 3.0 (CTCAEv3) developed by the U.S. National Cancer Institute [32]. For example, for hyperkalemia, severity of the $\mathrm{ADE}$ is classified as mild if the potassium concentration is higher than the upper limit of normal $(5.5 \mathrm{mmol} / \mathrm{L})$, as moderate if higher than $5.5-6.0 \mathrm{mmol} / \mathrm{L}$, as severe if higher than $6.0-7.0 \mathrm{mmol} / \mathrm{L}$, and as life-threatening if $>7.0 \mathrm{mmol} /$ L. Medication errors were classified according to the Dutch Central Medication Incidents Registration [33] and defined as errors in drug prescribing, transcribing, processing, compounding, stocking, dispensing, administering, or monitoring [33]. To assess if an medication error occurred, we utilized prevailing national [34] and local pharmacotherapeutic guidelines, as well as all alerts generated by the CDSSs operating in the participating hospitals.

The expert team assessed an ADE as unrecognized if, based on the patient charts reviewed, no indication was found that a medical team involved recognized patient harm as being medication related and/or no certain documented actions were targeted at that specific ADE.

During the scheduled meetings, the experts reached consensus on all aspects of the ADE assessment for an ADE to be included.

\section{Main outcome measures}

The main outcome measures were: (1) rate of ADEs present upon admission and (2) rate of ADEs occurring during the hospital stay. Both outcomes were expressed as rates per 100 hospitalizations.

\section{Statistical methods}

Descriptive statistics were applied for the analysis of patient characteristics, including means, standard deviations (SD), medians, and percentiles. To test for differences between patients included in the three hospitals, normally distributed continuous variables were compared using a one-way analysis of variance test and categorical variables were analyzed by using the chi-square test. Non-normally distributed continuous variables were compared using the Kruskall-Wallis test.

To compare the distributions of ADE severity, causality, type of harm manifestation, and type of events between unrecognized and recognized ADEs, we used the chisquare test or Fisher's exact test.

Multivariable backward logistic regression analyses were conducted to determine which patient factors were independently associated with no recognition of ADEs present upon admission and which factors led to no recognition of ADEs occurring during hospitalization. Variables in the model for no recognition of ADEs present upon admission included age, sex, number of preadmission medications, the type of admission (elective or acute), the presence of cognitive impairment on admission (yes/no), and the Charlson Comorbidity Index score [35]. Variables in the model for no recognition of ADEs occurring during the hospital stay included age, sex, number of hospital medications, length of stay on an Internal Medicine ward, the presence of cognitive impairment on admission (yes/no), and the Charlson Comorbidity Index score [35]. A $p$ value of $<0.05$ was considered to be statistically significant. Computer software 
SPSS ver. 18.0 (SPSS, Chicago, IL) was used for the calculations.

Ethical considerations

The WINGS study protocol [24] was presented to The Medical Ethics Committee of the University of Amsterdam. The Medical Ethics Committee discussed the protocol and exempted it from review and official approval. According to the Dutch Medical Research Involving Human Subjects Act, such a review and approval were not required because the study did not involve direct interaction with human subjects. This research used retrospective patient chart review to assess the extent of suboptimal care related to ADEs. Therefore, the integrity of patients was not influenced, and all patient data were analyzed anonymously by coding each patient included in the study by a 6 -digit number.

\section{Results}

Study population

Demographic characteristics of the 250 patients included in the study are shown in Table 1. The three groups of patients in the participating hospitals only differed in the median length of hospital stay on an Internal Medicine ward (median, with 25th and 75th percentile: AMC, 5.6 days (3.6, 7.9 days); WFG, 5.9 days (2.8, 8.1 days); $\mathrm{SH}, 7.4$ days (4.8, 11.8 days); $p=0.025)$. Therefore, patients' characteristics are in Table 1 presented after pooling.

\section{Main outcomes}

A total of 269 ADEs in 164 patients were identified. We found 60.4 ADEs (95 \% CI 51.5-70.8) present upon admission per 100 hospitalizations (151 ADEs), of which $19.9 \%(30 / 151)$ remained unrecognized during the subsequent hospitalization. During the hospital stay, we found 47.2 ADEs (95\% CI 39.4-56.5) per 100 hospitalizations (118 ADEs) to have occurred, of which $20.3 \%$ (24/118) remained unrecognized (Table 2). When only severe, life-threatening, or fatal ADEs were considered, the overall proportion of unrecognized ADEs decreased from 20.1 to $7.8 \%$. When only ADEs assessed as having nearly certain or probable event-drug causality were considered, the overall proportion of unrecognized ADEs decreased from 20.1 to $15.2 \%$.

The expert team assessed 135 ADEs as preventable $(50.2 \%)$, i.e., caused by medication errors, of which the medical teams did not recognize $30.4 \%$. Medication errors most often identified were: omissions in prescribing (25.2\%),
Table 1 Patient characteristics

\begin{tabular}{|c|c|}
\hline Characteristic & Total $(n=250)$ \\
\hline Age, years $($ mean $\pm \mathrm{SD})$ & $76.9 \pm 7.5$ \\
\hline Female, $n(\%)$ & $133(53.2)$ \\
\hline Living independent, $n(\%)$ & $211(84.4)$ \\
\hline Acute admission, $n(\%)$ & $213(85.2)$ \\
\hline Length of stay, days, median ( 25 th, 75 th percentile) & $5.9(3.6,9.6)$ \\
\hline \multicolumn{2}{|l|}{ Specialty of wards, $n(\%)$} \\
\hline General internal medicine & $98(39.2)$ \\
\hline Gastroenterology & $51(20.4)$ \\
\hline Nephrology & $46(18.4)$ \\
\hline Oncology and hematology & $37(14.8)$ \\
\hline Rheumatology & $18(7.2)$ \\
\hline Number of preadmission medications (mean \pm SD) & $7.3 \pm 3.2$ \\
\hline Number of hospital medications (mean \pm SD) & $11.0 \pm 4.1$ \\
\hline Number of concomitant diseases (mean $\pm \mathrm{SD}$ ) & $3.16 \pm 1.7$ \\
\hline \multicolumn{2}{|l|}{ Most frequent types of diseases, $n(\%)$} \\
\hline Cardiovascular & 179 (71.6) \\
\hline Malignancy & $94(37.6)$ \\
\hline Diabetes mellitus & $84(33.6)$ \\
\hline Muscle skeletal & $52(20.8)$ \\
\hline Renal & $41(16.4)$ \\
\hline Pulmonary & $39(15.6)$ \\
\hline Gastrointestinal & $30(12.0)$ \\
\hline Neurologic & $22(8.8)$ \\
\hline Psychologic & $15(6.0)$ \\
\hline \multicolumn{2}{|l|}{ Charlson Comorbidity Index score, $n(\%)$} \\
\hline 0 points & $24(9.6)$ \\
\hline $1-2$ points & $108(43.2)$ \\
\hline $3-4$ points & $63(25.2)$ \\
\hline$\geq 5$ points & $55(22.0)$ \\
\hline $\operatorname{MDRD} \mathrm{GGFR}^{\mathrm{b}}\left(\mathrm{ml} / \mathrm{min} / 1.73 \mathrm{~m}^{2}\right), n(\%)$ & $(n=240)$ \\
\hline$\geq 90$ & $21(8.8)$ \\
\hline $60-89$ & $73(30.4)$ \\
\hline $29-59$ & $88(36.7)$ \\
\hline $15-28$ & $34(14.2)$ \\
\hline$<15$ & $24(10.0)$ \\
\hline
\end{tabular}

SD, Standard deviation; MDRD study, Modification of Diet in Renal Disease study; eGFR, estimated glomerular filtration rate

${ }^{a}$ Length of stay on the Internal Medicine wards

${ }^{\mathrm{b}}$ For 10 patients no laboratory tests were run during the hospital stay to assess renal function

prescribing of too high or too low doses $(25.2 \%)$, prescribing of medication while contra-indicated (20.0\%), wrong pharmacotherapy choice for a known indication (excluding economic considerations) (11.1\%), drug-drug interactions (combinations should have been avoided or dosages adjusted) (7.4\%), drug administration errors (5.9\%), and lack of TDM $(5.2 \%)$. 
Table 2 Characteristics of adverse drug events identified and their in-hospital recognition by medical teams

\begin{tabular}{|c|c|c|c|}
\hline Characteristics & $\begin{array}{l}\text { Unrecognized ADEs } \\
(n=54)\end{array}$ & $\begin{array}{l}\text { Recognized ADEs } \\
(n=215)\end{array}$ & $\begin{array}{l}p \text { value and degrees } \\
\text { of freedom }\end{array}$ \\
\hline \multicolumn{4}{|l|}{ Time of identification } \\
\hline $\begin{array}{l}\text { ADE present upon admission } \\
\text { ADE occurred during the hospital stay }\end{array}$ & $\begin{array}{l}30(55.6) \\
24(44.4)\end{array}$ & $\begin{array}{l}121(56,3) \\
94(43,7)\end{array}$ & $0.924 ; d f=1$ \\
\hline \multicolumn{4}{|l|}{ Severity } \\
\hline $\begin{array}{l}\text { Mild to moderate } \\
\text { Severe or worse (life-threatening or fatal) }\end{array}$ & $\begin{array}{l}33(61.1) \\
21(38.9)\end{array}$ & $\begin{array}{l}109(49.3) \\
106(50.7)\end{array}$ & $0.171 ; d f=1$ \\
\hline \multicolumn{4}{|l|}{ Causality } \\
\hline $\begin{array}{l}\text { Nearly certain or probable/likely } \\
\text { Possible }\end{array}$ & $\begin{array}{l}41(75.9) \\
13(24.1)\end{array}$ & $\begin{array}{l}191(88.8) \\
24(11.2)\end{array}$ & $0.014 ; d f=1$ \\
\hline \multicolumn{4}{|l|}{ Preventability } \\
\hline $\begin{array}{l}\text { Non-preventable } \\
\text { Preventable }\end{array}$ & $\begin{array}{l}13(24.1) \\
41(75.9)\end{array}$ & $\begin{array}{l}121(56.3) \\
94(43.7)\end{array}$ & $<0.001 ; d f=1$ \\
\hline \multicolumn{4}{|l|}{ Type of events } \\
\hline $\begin{array}{l}\text { Clinical symptom } \\
\text { Laboratory abnormality }\end{array}$ & $\begin{array}{l}27(50.0) \\
27(50.0)\end{array}$ & $\begin{array}{l}135(62.8) \\
80(37.2)\end{array}$ & $0.086 ; d f=1$ \\
\hline \multicolumn{4}{|l|}{ Type of harm manifestation } \\
\hline $\begin{array}{l}\text { New harm } \\
\text { Sustained/worsened harm or delayed recovery from harm }\end{array}$ & $\begin{array}{l}9(16.7) \\
45(83.3)\end{array}$ & $\begin{array}{l}174(80.9) \\
41(19.1)\end{array}$ & $<0.001 ; d f=1$ \\
\hline
\end{tabular}

ADE, Adverse drug event; df, degrees of freedom

Data are presented as the number of patients, with the percentage given in parenthesis

The intra-rater agreement of the involved expert team (initial vs. second review by LA and CS 1 year later) was substantial for presence of an $\mathrm{ADE}(\mathrm{K}=0.74)$, preventability of ADEs $(K=0.68)$, and severity $(\kappa=0.93)$.

\section{Characteristics of recognized and unrecognized ADEs}

A substantial number of ADEs identified by the expert team caused serious patient harm $(47.2 \% ; 127 / 269$ ADEs were scored as severe, life-threatening, or fatal). Of these ADEs $16.5 \%$ were not recognized by the medical teams (Table 2). We identified four fatal ADEs (all recognized by the medical teams) and 38 ADEs which caused life-threatening patient harm [5 (15.2\%) unrecognized by the medical teams]. Differences in distributions between the unrecognized and recognized ADEs were found for causality $(p=0.014, d f=1)$, preventability $(p<0.001, d f=1)$, and type of harm due to an ADE $(p<0.001, d f=1)$. In comparison with recognized ADEs, unrecognized ADEs were more often ADEs with a possible drug-event causality score, preventable ADEs, and less often ADEs which resulted in new symptoms or pathology. The most frequent events related to ADEs $(87.0 \%$ of all ADEs identified), their severity and causality, and recognition are shown in Table 3 , as well as medications most frequently involved in those ADEs listed per event type.

All ADEs resulting in hemorrhage, raised International Normalization Ratio (INR), skin reaction, and, except for one event per category, all ADEs resulting in constipation or ileus, and hyper- and hypoglycemia were recognized by the medical teams involved (Table 3). Causality of those events with medication was assessed as nearly certain or probable for $64.3 \%$ of the ADEs resulting in raised INR to $100.0 \%$ of the skin reaction ADEs and ADEs resulting in constipation/ileus. More than half of ADEs resulting in hemorrhage $(56.5 \%)$ and hyper-hypoglycemia (66.7 \%), and all ADEs resulting in raised INR $(100.0 \%)$ were severe or worse according to the CTCAEv3 criteria [32],

The proportions of unrecognized ADEs were higher for events in the following categories: central nervous system (CNS), (23.8\% unrecognized), hypotension/bradycardia (27.8 \% unrecognized), anemia (40.0\% unrecognized), nausea and vomiting (44.4\% unrecognized), raised creatinine/renal insufficiency (47.1 \% unrecognized), and raised liver transaminases (LTs)/liver insufficiency (53.3\% unrecognized) (Table 3 ). Of the latter two categories, $75.5 \%$ manifested as an abnormal laboratory test result only. The majority of these ADEs was assessed as having nearly certain or probable drug causality (66.7 \% for CNS events to $94.4 \%$ for hypotension/bradycardia). The proportions of severe or worse ADEs according to CTCAEv3 criteria [32] were, except for CNS events, lower $(26.7 \%$ for anemia to $44.4 \%$ for hypotension/bradycardia) than those for ADEs which were (almost) all recognized. Of the CNS events, $66.7 \%$ was scored as severe or worse. 
Table 3 Most frequently identified ADEs and their recognition by the medical teams during the hospital stay

\begin{tabular}{|c|c|c|c|}
\hline $\begin{array}{l}\text { Type of events } \\
\text { (examples of most often involved medication) }\end{array}$ & $\begin{array}{l}\text { No. of all events identified by the } \\
\text { expert team (\% unrecognized })\end{array}$ & $\begin{array}{l}\text { No. of severe or worse } \\
\text { events ( } \% \text { unrecognized) }\end{array}$ & $\begin{array}{l}\text { No. of nearly certain } \\
\text { and probable events } \\
\text { (\% unrecognized) }\end{array}$ \\
\hline Electrolyte disturbances (diuretics/RAAS inhibitors) & $43(18.6)$ & $11(27.3)$ & $34(17.6)$ \\
\hline $\begin{array}{l}\text { Hemorrhage (coumarines/anti-platelet medication, } \\
\text { omissions of gastro-protective medication) }\end{array}$ & $23(0.0)$ & $13(0.0)$ & $19(0.0)$ \\
\hline $\begin{array}{l}\text { Central nervous system events }{ }^{\mathrm{a}} \\
\text { (opiates/benzodiazepines/beta-blockers) }\end{array}$ & $21(23.8)$ & $14(21.4)$ & $14(7.1)$ \\
\hline $\begin{array}{l}\text { Hypotension/bradycardia } \\
\text { (beta-blockers/diuretics/digoxin) }\end{array}$ & $18(27.8)$ & $8(12.5)$ & $17(29.4)$ \\
\hline $\begin{array}{l}\text { Delayed recovery from an infection or } \\
\text { sustained infections }{ }^{b} \text { (antibiotics) }\end{array}$ & $18(11.1)$ & $15(13.3)$ & $16(6.3)$ \\
\hline $\begin{array}{l}\text { Raised creatinine/renal insufficiency } \\
\text { (antibiotics/NSAIDs/RAAS inhibitors/diuretics) }\end{array}$ & $17(47.1)$ & $6(33.3)$ & $15(53.3)$ \\
\hline $\begin{array}{l}\text { Constipation or ileus } \\
\text { (omission of laxatives while taking opiates) }\end{array}$ & $16(6.3)$ & $6(0.0)$ & $16(6.3)$ \\
\hline $\begin{array}{l}\text { Hyper- and hypoglycemia } \\
\text { (anti-diabetic drugs/corticosteroids) }\end{array}$ & $15(6.7)$ & $10(0.0)$ & $14(7.1)$ \\
\hline $\begin{array}{l}\text { Raised LTs/liver insufficiency } \\
\text { (anti-diabetic drugs/antibiotics/statins) }\end{array}$ & $15(53.3)$ & $7(85.7)$ & $10(60.0)$ \\
\hline Anemia $^{c}$ (omission of iron supplements) & $15(40.0)$ & $4(25.0)$ & $13(38.5)$ \\
\hline Raised INR (coumarines) & $14(0.0)$ & $9(0.0)$ & $14(0.0)$ \\
\hline Skin reactions (intra-venous antibiotics) & $10(0.0)$ & $0(0.0)$ & $10(0.0)$ \\
\hline Nausea and vomiting (antibiotics) & $9(44.4)$ & $3(33.3)$ & $7(28.6)$ \\
\hline
\end{tabular}

RAAS, Renin-angiotensin-aldosterone system; NSAIDs, non-steroidal anti-inflammatory drugs; LTs, liver transaminases; INR, International Normalization Ratio

${ }^{a}$ Mainly delirium (7 ADEs), extrapyramidal symptoms (4 ADEs), falls (4 ADEs), and somnolence/drowsiness (3 ADEs)

${ }^{\mathrm{b}}$ Delayed recovery from or sustained infections were primarily caused by inappropriate empirical antibiotic therapy choice, too short treatment regimes, or inappropriate route of antibiotic administration (oral where intravenous was indicated)

${ }^{\mathrm{c}}$ Mainly cases of older patients with chronic cardiovascular disease who were hospitalized due to (excessive) blood loss, in whom anemia was not sufficiently corrected to decrease risks involved with low hemoglobin values

\section{Multivariable analyses}

The Charlson Comorbidity Index score [32] was the only characteristic independently associated with no recognition of ADEs present upon admission [odds ratio (OR) 0.76, $95 \% \mathrm{CI}, 0.59-0.97 ; p=0.026)$. Patients with cognitive impairment on admission seemed to have a higher risk for unrecognized ADEs being present upon admission in comparison to patients without cognitive impairment (OR 2.4, $95 \%$ CI $1.00-5.85 ; p=0.05)$. No independently associated patient characteristics were found for having an unrecognized ADE occurring during the hospital stay.

\section{Discussion}

Our study focused on medical teams' ability to recognize ADEs in hospitalized older patients aged 65 years or older and included an assessment of both ADEs present upon admission and ADEs occurring during the hospital stay. We found that of all 269 ADEs identified by our expert team, $20 \%$ remained unrecognized by medical teams during the hospital stay. Of the unrecognized ADEs, more than a half $(56 \%)$ were ADEs present upon admission, and the majority $(76 \%)$ were ADEs caused by medication errors. Our results show that patients' characteristics as well as ADE characteristics impact the ability of medical teams to recognize ADEs in older inpatients.

The rates of both ADEs present upon admission (60.4 per 100 hospitalizations) and ADEs occurring during the hospital stay (47.2 per 100 hospitalizations) identified in this study are markedly higher than those reported in previous ADE studies in older patients [5, 12-22]. These differences can partly be explained by differences in the type of identification method used, the clinical setting, and in the definitions of the outcomes applied [25, 36, 37]. In this study, we used a definition of an ADE which included not only new ADEs, but also worsened and sustained harm or delayed recovery from harm due to both preventable and non-preventable ADEs [4, 24]. Furthermore, by utilizing an adapted IHI ADE trigger-tool [29] as an aid, our chart review was more structured and may, therefore, be more accurate $[27,30,38]$. We also deployed a physician-pharmacist team to review patient charts because the professional knowledge of this 
combination is complementary [39]. These combined aspects of our methodology may have resulted in a higher number of ADEs being identified. In addition, we included patients with five or more medications on the day of admission. It is well acknowledged that a higher number of medications significantly increases the risk of an ADE [40]. The distribution of ADEs in our study per severity category, however, is comparable to that in other published ADE studies reporting on severity classification $[23,41]$, indicating that the high ADE yield gained in this study was, therefore, also not merely a result of a higher identification of less clinically relevant ADEs.

Although a direct comparison of our results on ADE recognition in older medical inpatients with those of previous studies is not possible, some aspects of our findings can be compared. In a study by Hohl et al. [23] conducted in an Emergency Department (ED) setting, the medical teams did not recognize $50 \%$ of ADEs present upon admission in older patients, whereas in our study this proportion was $20 \%$. This lower proportion can be explained by several factors. First, the ED study of Holhl et al. [23] was conducted in a Canadian hospital [23] and our study was conducted in three hospitals in the Netherlands. As such, the level of medical training in geriatrics and/or ADEs awareness may differ between the physicians involved in these two studies. Differences between healthcare settings are known to have an impact on ADE rates [36]. Second, in comparison to the relatively short ED visit, the time available to critically review admission medication during the hospital stay is longer. Third, because more than $80 \%$ of our patients were acutely admitted, they were often first seen in the ED. Hospital admission summaries written by ED physician's sometimes included possible medication-related causes promoting further examination by the treating physicians on medical wards. Interestingly, the percentage of unrecognized ADEs in our study is in line with that reported in a study in a general inpatient population where $24 \%$ of ADEs were not recognized by the medical team [11]. Given the complexity of older patients' cases, one could expect the proportion of unrecognized ADEs in our study to be much higher. Unfortunately, detailed data on the type of unrecognized ADEs were not presented by Nebeker et al. [11], which hampers further exploration of this point.

Patient characteristics and ADEs recognition

The results of our multivariate analyses showed that the odds for having an unrecognized ADE on admission decreased by $24 \%$ with each one point increase in the Charlson Comorbidity Index score [35] (95\% CI 0.59-0.97; $p=0.026$ ), while these odds appeared to be 2.4-fold higher in patients with cognitive impairment (95\% CI $1.00-5.85 ; p=0.05)$. The former results indicate that the physicians were well aware of the frail state of multi-morbid patients; the latter results suggest, however, that they were insufficiently aware of medication-related harm in patients with cognitive impairment on admission. A possible explanation for the better recognition of ADEs in multi-morbid patients is probably the investment of more time and/or involvement of other medical specialties. Previous studies have shown that a multidisciplinary approach is successful in improving prescribing in older patients [42-44]. Cognitive impairment is a wellknown and highly prevalent atypical symptom in hospitalized elderly patients [45]. Atypical disease presentation often hampers correct and timely diagnosis and treatment [9]. Therefore, such presentation may be an extra barrier in distinguishing between disease and medications as a cause of patients' symptoms that are present at the time of admission.

\section{Characteristics and recognition of ADEs}

In our study, recognized ADEs were more often ADEs manifesting as new symptoms $(p<0.001 ; d f=1)$. This finding is in line with the results reported by Hohl et al. [23] who found that ED physicians were most skillful in recognizing ADEs that represented patients' chief complaints. In a daily practice on the wards, physicians tend to focus first on new symptoms when making differential diagnoses. The most plausible causes are listed, and actions prioritized according to urgency and/or severity of the symptoms. Worsening of existing complains, delayed recovery, or no clinical improvement are probably more often associated with progression of the underlying pathology or the frail state of an older patient than with a drug effect.

As already mentioned, the task of distinguishing between an ADE and other causes of an event in often multi-morbid, polymedicated older inpatients is challenging $[6,9]$. Our results show that a strong causality between an event and a drug (nearly certain or probable ADEs) improves the ability of a physician to recognize ADEs $(p=0.014, d f=1)$. The essential distinctions between nearly certain/probable and possible drug-event causality are that in the latter case there may be another equally likely explanation for the event and/ or there is no information or uncertainty regarding what has happened after the suspected medication was stopped [31]. Therefore, it is likely to assume that possible ADEs are more easily missed. Not recognizing possible ADEs can, however, have serious consequences, as illustrated by one of our cases - that of a 90-year-old man, recently started on mirtazapine $15 \mathrm{mg}$ once daily for depression, presented with dyspnoea, peripheral edema, and somnolence. The reported incidence of somnolence with mirtazapine use is $>1-10 \%$ and of peripheral edema $>10 \%$. The patient was, however, diagnosed with pneumonia, and antibiotic treatment was initiated. The peripheral edema was treated with intravenous furosemide boluses; treatment with mirtazapine was 
continued. One day post-discharge, the patient was readmitted with increased somnolence and peripheral edema. After consulting a geriatrician, mirtazapine was discontinued, with subsequent resolution of the somnolence and peripheral edema.

In our study, CNS events, such as somnolence or delirium, as well as hypotension/bradycardia, anemia, nausea/ vomiting, raised creatinine/renal insufficiency, and raised LTs/liver insufficiency were often unrecognized as being drug-related ( $>20 \%$ unrecognized). These less wellrecognized events are examples of symptoms mimicking the presentation of various underlying pathologies and are less specific side-effects of medications. Moreover, in our study, these types of ADEs represented $40 \%$ of the most frequently identified ADEs (Table 3) and have also been reported as frequent events in other ADE studies in older inpatients [5, 12-22]. It would appear that sufficient pharmacotherapeutic and geriatric knowledge is necessary to be able to identify these evidently more challenging ADEs [43, 44]. In the hospitals participating in this study, the day-today care of inpatients is, however, provided by mostly junior medical residents with 1 or 2 years of clinical experience. Studies on the level of geriatric competencies of medical residents show that there are gaps in their skills and knowledge that need to be addressed to ensure that the growing group of older inpatients receive safe care [46, 47]. In case of ADEs resulting in raised creatinine/renal insufficiency and raised LTs/liver insufficiency, the fact that majority of these resulted in abnormal laboratory values only (76\%) may additionally have attributed to the lower recognition of these events $(p=0.086, d f=1)$. In the study by Hohl et al. [23], the ER physicians were also less proficient at detecting ADEs which resulted in abnormal laboratory values, i.e., the so-called "silent ADEs".

In contrast, ADEs resulting in hemorrhage, raised INR, constipation/ileus, skin reactions, and hyper/hypoglycemia were (almost) all recognized as being drug-related. These ADEs are examples of events with clinically apparent consequences and are very common and specific side-effects of medications. For example, the INR is often closely monitored during the hospital stay in patients taking coumarines. According to CTCAEv3 criteria [32], a severely raised INR implies an INR twofold the upper limit of normal (ULN) (9/ 14 cases of raised INR in our study). For atrial fibrillation, the INR target range is 2.5 to 3.5 , and twofold the ULN indicates an INR of $>7.0$. This clinically relevant rise, a known effect and side-effect of coumarines, was, therefore, easily noticed (100\% recognized). The fact that the majority of these well-recognized ADEs caused severe or worse patient harm (57-100\%) may also have contributed to better recognition. The unrecognized ADEs seem more likely to be ADEs of mild or moderate severity $(p=0.171, d f=1)$.
Last but not least, in our study the majority of ADEs (70\%) occurring during the hospital stay were caused by medication errors. Prescribing contra-indicated medications, dosing errors, and drug omissions accounted for $70 \%$ of all errors identified. Moreover, unrecognized ADEs were significantly more often preventable ADEs $(p<0.001)$. Many medications used by older patients are lifelong treatments, often prescribed (previously) by other medical specialists or general practitioners for known therapy needs and conditions at that time [6]. However, these conditions and needs can change, and medication once chosen could become inappropriate [6]. Physicians' reluctance to change or question drug therapies prescribed by colleagues is a well-known phenomenon [48] and a possible reason why (home) medication, even with errors, was continued unjustifiably.

\section{Limitations}

Our study has a number of limitations. First, methods based on expert opinion in the identification of ADEs are known to have a low agreement between the experts involved [49]. Given the obvious differences in knowledge and expertise between pharmacists and physicians, such a disagreement is, however, expected [50]. Yet, exactly because of these differences, pharmacists and physicians are complementary experts in terms of ADE identification [39]. Differences between our two experts regarding their judgments on ADE causality, severity, preventability, and recognition were resolved by consensus. Moreover, the identification and assessment of ADEs by our expert team were reproducible. Second, because we identified ADEs based on a retrospective patient chart review, a registration bias may have occurred. Although a prospective ADE identification method has been shown, especially for preventable ADEs, to provide more veracious results [51], an unresolved dilemma remains because the prospective method can also bias results given physicians' awareness of data collection. To use the data presented in this manuscript for an evaluation of future interventions, we determined that a retrospective method was more suitable to our needs. Third, a patient chart review method is especially useful to identify preventable ADEs due to prescribing errors and less helpful to identify preventable ADEs due to administration errors [52]. This may explain why administration errors accounted for only $6 \%$ of the preventable ADEs identified in this study. We were, however, mainly interested in the suboptimal care from the medical perspective and less from the nursing perspective. Although administration errors are frequent, the majority of these errors do not lead to ADEs [3]. Finally, the measurement of quality of care based on chart reviews is prone for documentation bias [53]. Actions taken and considerations regarding the choice of therapy may not be evident from what was recorded in patient charts and 
could, therefore, be considered inappropriate. However, it is also well-known that actions documented in patients files are not always performed [53]. Therefore, we collected among other things medical files, nursing files, medication charts, medical correspondence, laboratory and diagnostic findings, discharge letters, and home and discharge medication lists. Our experts considered all of these different types of sources during the structured assessment of the ADEs. Consequently, we are confident that our chart review provides veracious results for both ADEs rates and their recognition by medical teams [54].

\section{Unanswered questions}

Medication errors often have a complex causality and arise not only from active errors, such as insufficient knowledge, but also from factors such as a lack of training in prescribing or insufficient supervisor's feedback on prescribing [55]. The opportunity to investigate these so-called error provoking and latent conditions was limited because we identified ADEs by a retrospective patient chart review. By involving the Internal Medicine staff and residents in a risk-analysis to design future interventions, we hope to gain more insight into these factors [56].

\section{Future research}

Our data were obtained in three different hospitals, which increases the generalizability of our results. However, because the degree of ADEs recognition may differ between medical specialties or countries [11, 23], more studies are needed to confirm our findings. Strategies such as the Screening Tool of Older Persons' potentially inappropriate Prescriptions (STOPP), Screening Tool to Alert doctors to the Right Treatment (STOP) [57], and quality indicators for in-hospital pharmaceutical care of elderly patients [58] have the potential to improve the recognition of ADEs by detecting inappropriate prescribing. Considering ADEs as a differential diagnosis in older patients should be a standard approach on admission and during the hospital stay. Medical education regarding ADEs, a regular and comprehensive medication review $[6,10,59]$, a daily participation of clinical pharmacists in medical teams on the wards [60-62], and CDSSs $[63,64]$ specific to older inpatients' medication risks $[65,66]$ could all be of an added value in reducing preventable ADEs and improving ADE recognition.

\section{Conclusions}

By applying a comprehensive measurement strategy that included the identification of ADEs present upon admission and those occurring during the hospital stay, followed by an assessment of medical teams' ability to recognize these ADEs, we were able to identify patient- and ADE-related factors influencing the ability of medical teams to recognize ADEs in older vulnerable patients. The medical teams involved performed best at recognizing ADEs manifesting as new or clinically apparent symptoms and those causing serious patient harm. Less specific ADEs mimicking underlying pathology, ADEs with only an abnormal laboratory value or mild to moderately severe ADEs were less well recognized. However, physicians should also aim at achieving timely recognition of such less critical and less evident ADEs to prevent future emergencies. The findings of this study suggest areas where physicians should focus their attention in order to further improve their ability to recognize ADEs.

Acknowledgments We thank all of the staff of the Internal Medicine and Hospital Pharmacy departments of the participating hospitals for their support, and in particular Wendy van den Berg, José Popma-de Koning, Anouk Verburg-Eisma, Carla Kamp, Vera Ruijter and Jolande van der Wildt for their assistance in data collection, and Miranda Roskam for building the database for the study. We would also like to acknowledge the help of pharmacy students Kayan Tsoi and Mila Tjoa in the data entry for this study.

Collaborators The following are members of WINGS (Ward-oriented pharmacy In Newly admitted Geriatric Seniors): Joost L.B. Hoekstra, $\mathrm{MD}, \mathrm{PhD}$, Department of Internal Medicine, and Minke E.P. Jansen, PharmD, MSc, Department of Hospital Pharmacy, Academic Medical Centre, Amsterdam, The Netherlands; Wim G. Meijer, MD, PhD, Department of Internal Medicine, and Bea M. van der Kleij, PharmD, MSc, Department of Hospital Pharmacy, Westfriesgasthuis Hospital, Hoorn, The Netherlands; Anne M. Lagaay, MD, PhD, Department of Internal Medicine and Geriatrics, Spaarne Hospital, Hoofddorp, The Netherlands; Ruud T.M. van der Hoeven, PharmD, MSc, Director of Pharmacy Foundation of Haarlem Hospitals, Haarlem, The Netherlands.

Funding The study was supported by an unrestricted research grant from the Netherlands Organization for Health Research and Development (ZonMW), The Hague, The Netherlands (Project number SG0000001). ZonMW had no role in the study design, data collection and analyses, interpretation of the results, or in the production of this manuscript.

\section{Conflicts of interest None.}

Open Access This article is distributed under the terms of the Creative Commons Attribution License which permits any use, distribution, and reproduction in any medium, provided the original author(s) and the source are credited.

\section{References}

1. de Vries EN, Ramrattan MA, Smorenburg SM, Gouma DJ, Boermeester MA (2008) The incidence and nature of inhospital adverse events: a systematic review. Qual Saf Health Care 17(3):216-223 
2. Classen DC, Pestotnik SL, Evans RS, Lloyd JF, Burke JP (1997) Adverse drug events in hospitalized patients. Excess length of stay, extra costs, and attributable mortality. JAMA 277:301-306

3. Krähenbühl-Melcher A, Schlienger R, Lampert M, Haschke M, Drewe J, Krähenbühl S (2007) Drug-related problems in hospitals: a review of the recent literature. Drug Saf 30:379-407

4. Committee of Experts on Management of Safety and Quality in Health Care (SP-SQS), Expert Group on Safe Medication Practices (2005) Glossary of terms related to patient and medication safety. SP-SQS, Strasbourg

5. Thomas EJ, Brennan TA (2000) Incidence and types of preventable adverse events in elderly patients: population based review of medical records. Br Med J 320:741-744

6. Steinman MA, Hanlon JT (2010) Managing Medications in Clinically Complex Elders: "There is Got to Be a Happy Medium.". JAMA 304:1592-601

7. Milton JC, Hill-Smith I, Jackson SHD (2008) Prescribing for older people. Br Med J 336:606-609

8. Mallet L, Spinewine A, Huang A (2007) The challenge of managing drug interactions in elderly people. Lancet 370:185-191

9. Samaras N, Chevalley T, Samaras D, Gold G (2010) Older patients in the emergency department: a review. Ann Emerg Med 56:261269

10. Rochon PA, Gurwitz JH (1997) Optimising drug treatment for elderly people: the prescribing cascade. Br Med J 315:1096-1099

11. Nebeker JR, Hoffman JM, Weir CR, Bennett CL, Hurdle JF (2005) High rates of adverse drug events in a highly computerized hospital. Arch Intern Med 165:1111-1116

12. Page RL, Ruscin JM (2006) The risk of adverse drug events and hospital-related morbidity and mortality among older adults with potentially inappropriate medication use. Am J Geriatr Pharmacother 4:297-305

13. Gray SL, Sager M, Lestico MR, Jalaluddin M (1998) Adverse drug events in hospitalized elderly. J Gerontol A Biol Med Sci 53:M59-63

14. Passarelli MCG, Jacob-Filho W, Figueras A (2005) Adverse drug reactions in an elderly hospitalised population: inappropriate prescription is a leading cause. Drugs Aging 22:767-777

15. Cecile M, Seux V, Pauly V, Tassy S, Reynaud-Levy O, Dalco O et al (2009) Adverse drug events in hospitalized elderly patients in a geriatric medicine unit: study of prevalence and risk factors. Rev Med Intern 30:393-400

16. Trivalle C, Cartier T, Verny C, Mathieu A-M, Davrinche P, Agostini $\mathrm{H}$ et al (2010) Identifying and preventing adverse drug events in elderly hospitalised patients: a randomised trial of a program to reduce adverse drug effects. J Nutr Health Aging 14:57-61

17. Azad N, Tierney M, Victor G, Kumar P (2002) Adverse drug events in the elderly population admitted to a tertiary care hospital. J Healthc Manag 47:295-305, discussion 305-306

18. Bowman L, Carlstedt BC, Hancock EF, Black CD (1996) Adverse drug reaction (ADR) occurrence and evaluation in elderly inpatients. Pharmacoepidemiol Drug Saf 5:9-18

19. Egger T, Dormann H, Ahne G, Runge U, Neubert A, CriegeeRieck M et al (2003) Identification of adverse drug reactions in geriatric inpatients using a computerised drug database. Drugs Aging 20:769-776

20. Laroche M-L, Charmes J-P, Nouaille Y, Fourrier A, Merle L (2006) Impact of hospitalisation in an acute medical geriatric unit on potentially inappropriate medication use. Drugs Aging 23:49-59

21. Sari ABA, Cracknell A, Sheldon TA (2008) Incidence, preventability and consequences of adverse events in older people: results of a retrospective case-note review. Age Ageing 37:265-269

22. Somers A, Petrovic M, Robays H, Bogaert M (2003) Reporting adverse drug reactions on a geriatric ward: a pilot project. Eur $\mathbf{J}$ Clin Pharmacol 58:707-714

23. Hohl CM, Robitaille C, Lord V, Dankoff J, Colacone A, Pham L et al (2005) Emergency physician recognition of adverse drug-related events in elder patients presenting to an emergency department. Acad Emerg Med 12:197-205

24. Klopotowska JE, Wierenga PC, de Rooij SE, Stuijt CC, Arisz L, Kuks PF et al (2011) The effect of an active on-ward participation of hospital pharmacists in Internal Medicine teams on preventable Adverse Drug Events in elderly inpatients: protocol of the WINGS study (Ward-oriented pharmacy In Newly admitted Geriatric Seniors). BMC Health Serv Res 11:124

25. Hakkarainen KM, Andersson Sundell K, Petzold MHS (2012) Methods for assessing the preventability of adverse drug events: a systematic review. Drug Saf 35:105-126

26. Nebeker JR, Barach P, Samore MH (2004) Clarifying adverse drug events: a clinician's guide to terminology, documentation, and reporting. Ann Intern Med 140:795-801

27. Morimoto T, Gandhi TK, Seger AC, Hsieh TC, Bates DW (2004) Adverse drug events and medication errors: detection and classification methods. Qual Saf Health Care 13:306-314

28. Brown C, Hofer T, Johal A, Thomson R, Nicholl J, Franklin BD et al (2008) An epistemology of patient safety research: a framework for study design and interpretation. Part 3. End points and measurement. Qual Saf Health Care 17:170-177

29. Institute for Healthcare Improvement (2007). IHI global trigger tool for measuring adverse events. Institute for Healthcare Improvement, Cambridge

30. Resar RK, Rozich JD, Classen D (2003) Methodology and rationale for the measurement of harm with trigger tools. Qual Saf Health Care Suppl 3:39-45

31. The Uppsala Monitoring Centre. The use of the WHO-UMC system for standardised case causality assessment. Available at: http://who-umc.org/Graphics/24734.pdf. Accessed 23 Mar 2012

32. Cancer Therapy Evaluation Program. Common terminology criteria for adverse events v3.0. Available at: http://ctep.cancer.gov/ protocoldevelopment/electronic_applications/docs/ctcaev3.pdf. Accessed 23 Mar 2012

33. Cheung KC, van den Bemt PM, Bouvy ML, Wensing M, De Smet PA (2011) A nationwide medication incidents reporting system in The Netherlands. J Am Med Inform Assoc 18:799-804

34. Dutch Drug Database. Available at: http://kennisbank.knmp.nl/. Accessed 23 Mar 2012

35. Charlson ME, Pompei P, Ales KL, MacKenzie CR (1978) A new method of classifying prognostic comorbidity in longitudinal studies: development and validation. J Chronic Dis 40:373-383

36. Leendertse AJ, Visser D, Egberts ACG, van Den Bemt PMLA (2010) The relationship between study characteristics and the prevalence of medication-related hospitalizations: a literature review and novel analysis. Drug Saf 33:233-244

37. Dean B (2003) Adverse drug events: what is the truth? Qual Saf Health Care 12:165-166

38. Rozich JD, Haraden CR, Resar RK (2003) Adverse drug event trigger tool: a practical methodology for measuring medication related harm. Qual Saf Health Care 12:194-200

39. Phansalkar S, Hoffman JM, Nebeker JR, Hurdle JF (2007) Pharmacists versus nonpharmacists in adverse drug event detection: a metaanalysis and systematic review. Am J Health Syst Pharm 64:842-849

40. Evans RS, Lloyd JF, Stoddard GJ, Nebeker JR, Samore MH (2005) Risk factors for adverse drug events: a 10-year analysis. Ann Pharmacother 39:1161-1168

41. Chan M, Nicklason F, Vial JH (2001) Adverse drug events as a cause of hospital admission in the elderly. Intern Med J 31:199-205

42. Kaur S, Mitchell G, Vitetta L, Roberts MS (2009) Interventions that can reduce inappropriate prescribing in the elderly: a systematic review. Drugs Aging 26:1013-1028

43. Lang PO, Hasso Y, Dramé M, Vogt-Ferrier N, Prudent M, Gold G et al (2010) Potentially inappropriate prescribing including underuse amongst older patients with cognitive or psychiatric comorbidities. Age Ageing 39:373-381 
44. Bakker FC, Robben SHM, Olde Rikkert MGM (2011) Effects of hospital-wide interventions to improve care for frail older inpatients: a systematic review. BMJ Qual Saf 20:680-691

45. Olde Rikkert MGM, Rigaud AS, van Hoeyweghen RJ, de Graaf J (2003) Geriatric syndromes: medical misnomer or progress in geriatrics? Neth J Med 61:83-87

46. Drickamer MA, Levy B, Irwin KS, Rohrbaugh RM (2006) Perceived needs for geriatric education by medical students, internal medicine residents and faculty. J Gen Intern Med 21:1230-1234

47. Warshaw GA, Bragg EJ, Thomas DC, Ho ML, Brewer DE (2006) Are internal medicine residency programs adequately preparing physicians to care for the baby boomers? A national survey from the Association of Directors of Geriatric Academic Programs Status of Geriatrics Workforce Study. J Am Geriatr Soc 54:1603-1609

48. Bain KT, Holmes HM, Beers MH, Maio V, Handler SM, Pauker SG (2008) Discontinuing medications: a novel approach for revising the prescribing stage of the medication-use process. J Am Geriatr Soc 56:1946-1952

49. Agbabiaka TB, Savović J, Ernst E (2008) Methods for causality assessment of adverse drug reactions: a systematic review. Drug Saf 31:21-37

50. van Doormaal JE, Mol PGM, van Den Bemt PMLA, Zaal RJ, Egberts ACG, Kosterink JGW et al (2008) Reliability of the assessment of preventable adverse drug events in daily clinical practice. Drug Saf 17:645-654

51. Michel P, Quenon JL, de Sarasqueta AM, Scemama O (2004) Comparison of three methods for estimating rates of adverse events and rates of preventable adverse events in acute care hospitals. Br Med J 328:199

52. Bates DW, Boyle DL, Vander Vliet MB, Schneider J, Leape L (1995) Relationship between medication errors and adverse drug events. J Gen Intern Med 10:199-205

53. Luck J, Peabody JW, Dresselhaus TR, Lee M, Glassman P (2000) How well does chart abstraction measure quality? A prospective comparison of standardized patients with the medical record. Am J Med 108:642-9

54. Egbring M, Far E, Knuth A, Roos M, Kirch W, Kullak-Ublick GA (2011) Performance of different data sources in identifying adverse drug events in hospitalized patients. Eur J Clin Pharmacol 67:909-18

55. Tully MP, Ashcroft DM, Dornan T, Lewis PJ, Taylor D, Wass V (2009) The causes of and factors associated with prescribing errors in hospital inpatients: a systematic review. Drug Saf 32:819-836
56. Spinewine A, Swine C, Dhillon S, Franklin BD, Tulkens PM, Wilmotte L et al (2005) Appropriateness of use of medicines in elderly inpatients: qualitative study. Br Med J 331:935

57. Gallagher PF, O'Connor MN, O'Mahony D (2011) Prevention of potentially inappropriate prescribing for elderly patients: a randomized controlled trial Using STOPP/START criteria. Clin Pharmacol Ther 89:845-854

58. Wierenga PC, Klopotowska JE, Smorenburg SM, van Kan HJ, Bijleveld YA, Dijkgraaf MG et al (2011) Quality indicators for in-hospital pharmaceutical care of Dutch elderly patients: development and validation of an ACOVE-based quality indicator set. Drugs Aging 28:295-304

59. van Dijk KN, van Asselt DZB, Vogel D, van Der Hooft CS, Van Roon EN, Brouwers JRBJ (2009) Effects of a structured medication review by geriatrician and clinical pharmacologist on appropriateness of pharmacotherapy in frail elderly inpatients. Tijdschr Gerontol Geriatr 40:72-78

60. Kaushal R, Bates DW, Abramson EL, Soukup JR, Goldmann DA (2008) Unit-based clinical pharmacists' prevention of serious medication errors in pediatric inpatients. Am J Health Syst Pharm 65:1254-1260

61. Leape LL, Cullen DJ, Clapp MD, Burdick E, Demonaco HJ, Erickson JI et al (1999) Pharmacist participation on physician rounds and adverse drug events in the intensive care unit. JAMA 282:267-720

62. Kucukarslan SN, Peters M, Mlynarek M, Nafziger DA (2003) Pharmacists on rounding teams reduce preventable adverse drug events in hospital general medicine units. Arch Intern Med 163:2014-2018

63. Rommers MK, Teepe-Twiss IM, Guchelaar HJ (2007) Preventing adverse drug events in hospital practice: an overview. Pharmacoepidemiol Drug Saf 16:1129-1135

64. Bates DW, Gawande A (2003) Improving safety with information technology. N Engl J Med 348:2526-2534

65. Fritz D, Ceschi A, Curkovic I, Huber M, Egbring M, KullakUblick GA, et al (2012) Comparative evaluation of three clinical decision support systems: prospective screening for medication errors in 100 medical inpatients. Eur J Clin Pharmacol [Epub ahead of print]

66. Griffey RT, Lo HG, Burdick E, Keohane C, Bates DW (2012) Guided medication dosing for elderly emergency patients using real-time, computerized decision support. J Am Med Inform Assoc 19:86-93 